University of Nebraska - Lincoln

DigitalCommons@University of Nebraska - Lincoln

Sociology Department, Faculty Publications

Sociology, Department of

Spring 2011

The Role of Interviewer Experience on Acquiescence

Kristen Olson

University of Nebraska-Lincoln, kolson5@unl.edu

Ipek Bilgen

University of Nebraska-Lincoln

Follow this and additional works at: https://digitalcommons.unl.edu/sociologyfacpub

Part of the Sociology Commons

Olson, Kristen and Bilgen, Ipek, "The Role of Interviewer Experience on Acquiescence" (2011). Sociology Department, Faculty Publications. 132.

https://digitalcommons.unl.edu/sociologyfacpub/132

This Article is brought to you for free and open access by the Sociology, Department of at DigitalCommons@University of Nebraska - Lincoln. It has been accepted for inclusion in Sociology Department, Faculty Publications by an authorized administrator of DigitalCommons@University of Nebraska - Lincoln. 
Published in Public Opinion Quarterly 75:1 (Spring 2011), pp. 99-114; doi: 10.1093/poq/ nfq067 Copyright (C) 2011 Kristen Olson and Ipek Bilgen. Published by Oxford University Press on behalf of the American Association for Public Opinion Research. Used by permission.

\title{
The Role of Interviewer Experience on Acquiescence
}

\section{Kristen Olson and Ipek Bilgen}

\author{
University of Nebraska-Lincoln \\ Corresponding author - Kristen Olson, Department of Sociology, 703 Oldfather Hall, \\ University of Nebraska-Lincoln, Lincoln, NE 68588, USA; email kolson5@unl.edu
}

\begin{abstract}
Experienced interviewers are commonly thought to achieve better quality survey data than inexperienced interviewers. Yet few empirical examinations of differences in data quality on attitudinal questions for experienced versus inexperienced interviewers exist. In this article, we examine whether experienced and inexperienced interviewers differ in their levels of a commonly evaluated data quality measure-acquiescence-in two national surveys. We hypothesize that experienced interviewers will have higher rates of acquiescence than inexperienced interviewers due to either differential pace or differential behaviors. We find that experienced interviewers obtain higher levels of acquiescent reports than do inexperienced interviewers, even after accounting for potential differences in interviewer and respondent characteristics. These differences across interviewers are not mediated by differential pace of the interview, as measured by interview length, implying that there may be differences in interview behaviors for experienced and inexperienced interviewers. We conclude with implications for survey practice and interviewer training and monitoring.
\end{abstract}

\section{Introduction}

A long-standing belief in survey research is that more experienced interviewers are "better" interviewers (e.g., Bailar, Bailey, and Stevens 1977;

Kristen Olson is an Assistant Professor of Sociology and Survey Research and Methodology (SRAM) at the University of Nebraska-Lincoln, Lincoln, NE, USA. Ipek Bilgen is a doctoral candidate at the SRAM program at the University of Nebraska-Lincoln, Lincoln, NE, USA. Both authors contributed equally to this research.

The ANES materials are based on work supported by, in alphabetical order, the National Science Foundation [SES-0118451] and the University of Michigan. The GSS materials were collected by NORC under a grant from the National Science Foundation as part of the National Data Program for the Social Sciences, No. 18, and distributed by the Roper Center. Any opinions, findings, and conclusions or recommendations expressed in these materials are those of the author(s) and do not necessarily reflect the views of the funding organizations. 
Singer, Frankel, and Glassman 1983). While experienced interviewers tend to have higher response rates than less experienced interviewers (Groves and Couper 1998), the empirical evidence for the effect of experienced interviewers on the quality of responses from survey respondents is less clear (Groves et al. 2004). Recent research has shown that more experienced interviewers obtain differing levels of drug use (Chromy et al. 2005; Hughes et al. 2002; but see Johnson et al. 2000), mental health problems (Cleary, Mechanic, and Weiss 1981), and other behavioral items (O'Muircheartaigh and Campanelli 1998) than inexperienced interviewers. Whether there is a difference in measurement errors for attitudinal questions such as acquiescence is less well understood. This article examines the relationship between interviewer experience and acquiescence in two surveys - the 2000 American National Election Studies and the 2006 General Social Survey.

Acquiescence, sometimes called "yea-saying," is a respondent's tendency to agree with survey questions regardless of their content (Schuman and Presser 1981). Acquiescence distorts conclusions made from surveys by artificially increasing levels of support for survey questions and changing relationships among survey items. To our knowledge, only one study has formally examined interviewer effects on acquiescence, ${ }^{1}$ finding significant variability across interviewers (Hox, de Leeuw, and Kreft 1991); differences in acquiescence across interviewer experience levels were not examined.

Why might interviewer experience affect acquiescence? If acquiescence is simply an individual respondent trait, then there should be no relationship between interviewer experience and acquiescence. Three respondentlevel hypotheses have been posited for why an individual might acquiesce to survey questions (Schuman and Presser 1981): a general psychological trait for saying "yes," a desire to be viewed in a positive light by the interviewer, or a lack of cognitive sophistication, increasing unwillingness to engage in all steps of the cognitive response process (Ross and Mirowsky 1984; Smith 1967; Narayan and Krosnick 1996). Two other explanations, however, yield predictions for more experienced interviewers obtaining higher rates of acquiescent reports.

First, deliberate attempts to create a positive atmosphere during an interview often are attributed to respondent efforts to defer to or not offend the interviewer (Ross and Mirowsky 1984). Yet interviewers also build rapport during the interview (Kahn and Cannell 1957). Interviewers may view obtaining "yes" answers as one way to do this and change behaviors or question wording accordingly (Houtkoop-Steenstra 1996, 1997; Houtkoop-Steenstra and Antaki 1997). Experienced interviewers also are more likely to feel rapport with respondents than are inexperienced interviewers (Goudy and Potter 1975-76). Thus, if experienced interviewers place a heavier premium

1. Race and sex of interviewers affect respondents' agreement rates with race- and sex-related questions (e.g., Davis 1997; Groves and Fultz 1985; Webster 1996), largely due to social desirability or differential question framing from the interviewer characteristics (Krysan and Couper 2003). 
on maintaining rapport than do inexperienced interviewers, they may have higher levels of acquiescent answers (Weiss 1968-69).

Second, more experienced interviewers have faster interviews, on average, than do less experienced interviewers (Olson and Peytchev 2007), hypothesized to arise because experienced interviewers place a greater emphasis on productivity (Groves et al. 2004, Chapter 9). The increased pace might create an environment where respondents have less time to think through their answers, thereby increasing their likelihood of satisficing (Narayan and Krosnick 1996; Holbrook, Green, and Krosnick 2003). As such, more experienced interviewers may have higher rates of acquiescent answers than do less experienced interviewers.

We expect the effect of experience to be nonlinear. New interviewers must become familiar with their role, drawing on behaviors they practiced during training (Olson and Peytchev 2007). More experienced interviewers may not receive training on basic interviewing techniques, relying on previous experience over training (Tarnai and Moore 2008). Additionally, interviewers who have previously conducted interviews using a particular questionnaire will be more comfortable with the questions, easing and speeding up its administration (Olson and Peytchev 2007). Thus, we expect the largest differences in acquiescence between interviewers with little or no experience and interviewers with some study-specific experience.

We include interviewer and respondent characteristics in the models to account for the lack of interpenetration (Mahalanobis 1946) and potentially confounding interviewer and respondent characteristics. Interviewer characteristics such as race, sex, age, and education may affect respondents' answers to attitudinal questions (Cleary, Mechanic, and Weiss 1981; Schuman and Converse 1971; Kane and Macaulay 1993; Krysan and Couper 2003). Additionally, differences across interviewers in data quality may reflect differences in respondent characteristics, such as education (Schuman and Presser 1981; Krosnick 2002), age (Knauper et al. 1997), race (Krysan and Couper 2003), and sex.

\section{Data and Methods}

Data. The data come from two surveys - the 2000 American National Election Survey (ANES) and the 2006 General Social Survey (GSS). The 2000 ANES included a face-to-face area probability survey of adults living in the United States (Burns et al. 2002), equal probability to the household level, and a random-digit-dial sample of telephone households. The pre-election survey in the ANES was conducted by the University of Michigan Survey Research Center during the nine weeks before the 2000 presidential election. The inperson and telephone response rates ${ }^{2}$ were 64.8 percent and 57.2 percent, re-

2. The 2000 ANES response rate is "Completed interviews/total number of potential respondents" (Burns et al. 2002, 27). 
Table 1. Number of Interviewers and Respondents and Mean Acquiescence Rate, 2000 American National Election Studies and 2006 General Social Survey

\begin{tabular}{lrr}
\hline & 2000 ANES & 2006 GSS \\
\hline Number of Interviewers & 115 & 179 \\
Total & 83 & 129 \\
Interviewers with 10+ interviews & 83 & 118 \\
Interviewers with complete acquiescence data & $76 \%$ & $78 \%$ \\
\% Interviewers with 1+ year of experience & & \\
Number of Respondents & 1807 & 4510 \\
$\quad$ Total & 1646 & 4255 \\
Interviewers with 10+ interviews & 1631 & 3917 \\
Interviewers with complete acquiescence data & 19.7 & 33.2 \\
Average number of respondents per interviewer & $33.1 \%$ & $49.9 \%$ \\
Mean Acquiescence Rate & & \\
\hline
\end{tabular}

spectively, for an overall response rate of 61.2 percent. Of the 115 interviewers and 1807 respondents, we include interviewers who conducted at least 10 interviews, yielding 83 interviewers and 1646 respondents. Due to item nonresponse, 83 interviewers and 1631 respondents provide usable data, with an average of 19.7 respondents per interviewer (Table 1).

The 2006 GSS is an area probability survey of U.S. English- and Spanishspeaking adults, conducted by the National Opinion Research Center (Davis and Smith 2007). As with the ANES, the 2006 GSS used both in-person and telephone modes; unlike the ANES, mode was not randomly assigned. The 2006 GSS is equal probability to the household level; nonresponding households were subsampled. The overall response rate was 71.2 percent (AAPOR RR5). The 2006 GSS had 179 interviewers and 4510 respondents; 129 interviewers interviewed at least 10 respondents, yielding 4255 respondents. Due to item nonresponse, we examine 118 interviewers and 3917 respondents, an average of 33.2 respondents per interviewer. ${ }^{3}$

Methods. Acquiescence is the percentage of "yes" or "strongly agree/ agree" answers provided by each respondent $j$ interviewed by interviewer $i$ out of the number of questions answered, that is,

$$
Y_{i j}=100 \times \frac{\text { "Yes" or "Agree/Strongly agree" } \text { response }_{i j}}{\text { questions answered }_{i j}}
$$

We selected attitudinal measures with explicit yes/no or agree/disagree response options (listed in the Appendix). The question topics vary across the two studies, although the response options are identical. In the ANES, the questions focus on attitudes toward political figures (Gore, Bush, Buchanan, and Clinton) and two political issues (replicating Holbrook, Green, and Kros-

3. Almost 90 percent of the missing cases are due to 11 interviewers with missing sex and race information. Little information is available at the interviewer level to impute these characteristics. 
nick 2003). As an omnibus survey, the GSS questions range widely, including abortion, police violence toward male citizens, suicide, discrimination toward African Americans, and attitudes about politicians. The mean acquiescence rate is 33.1 percent in the ANES and 49.9 percent in the GSS.

The key independent variable is interviewer experience. The ANES and GSS provide information on only general experience, not study-specific experience. We dichotomize experience as less than one year versus one year or more employed by the organization. Roughly three-fourths of the interviewers in each study had at least one year of experience (Table 1).

Interviewer characteristics include interviewer age, sex, and race. The mean interviewer age is 52 years old in the ANES and 53 years old in the GSS. About 79 percent of GSS interviewers and 87 percent of ANES interviewers are female. In the GSS, 22 percent of the interviewers are non-white, compared to seven percent in the ANES. The ANES measures interviewer education as high school graduate (19 percent), some college (33 percent), college degree (30 percent), or master's degree (19 percent). We also account for administration mode -7 and 47 percent of the GSS and ANES interviews, respectively, are conducted by telephone.

Respondent characteristics include age, education, race, sex, and length of interview. The mean age of respondents in each study is 47 years old. Respondent education is measured by highest obtained degree, ranging from eighth grade or less (in the ANES) or less than high school (in the GSS) to a graduate degree, with the mean education level slightly below some college in both studies. Twenty-seven percent of respondents are non-white in the GSS, with 22 percent in the ANES; 56 percent of respondents in both studies are female. The average ANES interview was 68 minutes $(\mathrm{SD}=23.4)$ long. The seven versions of the GSS questionnaire vary in length. Version 7 has an average length of 71 minutes (SD $=24.9)$, compared to greater than 90 minutes for the other versions.

Our analyses proceed in four steps. First, we test for statistically significant variation across interviewers using chi-square tests from a two-level intercept-only random effects model (Raudenbush and Bryk 2002). We summarize the variable effects of interviewers on acquiescence using the intraclass correlation coefficient, $\rho_{\text {int }}$ (Kish 1962; O'Muircheartaigh and Campanelli 1998).

We then examine the relationship between interviewer experience and acquiescence using hierarchical linear models, accounting for respondent and interviewer characteristics, estimated in SAS 9.2. Multilevel models account for the clustering of respondents within interviewers and facilitate estimating interviewer-variance components when the number of respondents per interviewer varies (Dijkstra 1983; Hox 1994; O'Muircheartaigh and Campanelli 1998; Raudenbush and Bryk 2002). The models account for a random intercept across interviewers; the remaining characteristics are constrained to be fixed across interviewers. We then examine the relationship between experience and the length of interview, followed by adding the natural logarithm of interview length to each acquiescence model. This analysis examines 
Table 2. Hierarchical Linear Model Regression Coefficients and Standard Errors, Variance Components, and Model Fit Statistics for the Acquiescence Models, 2000 American National Election Studies and 2006 General Social Survey (standard errors in parentheses)

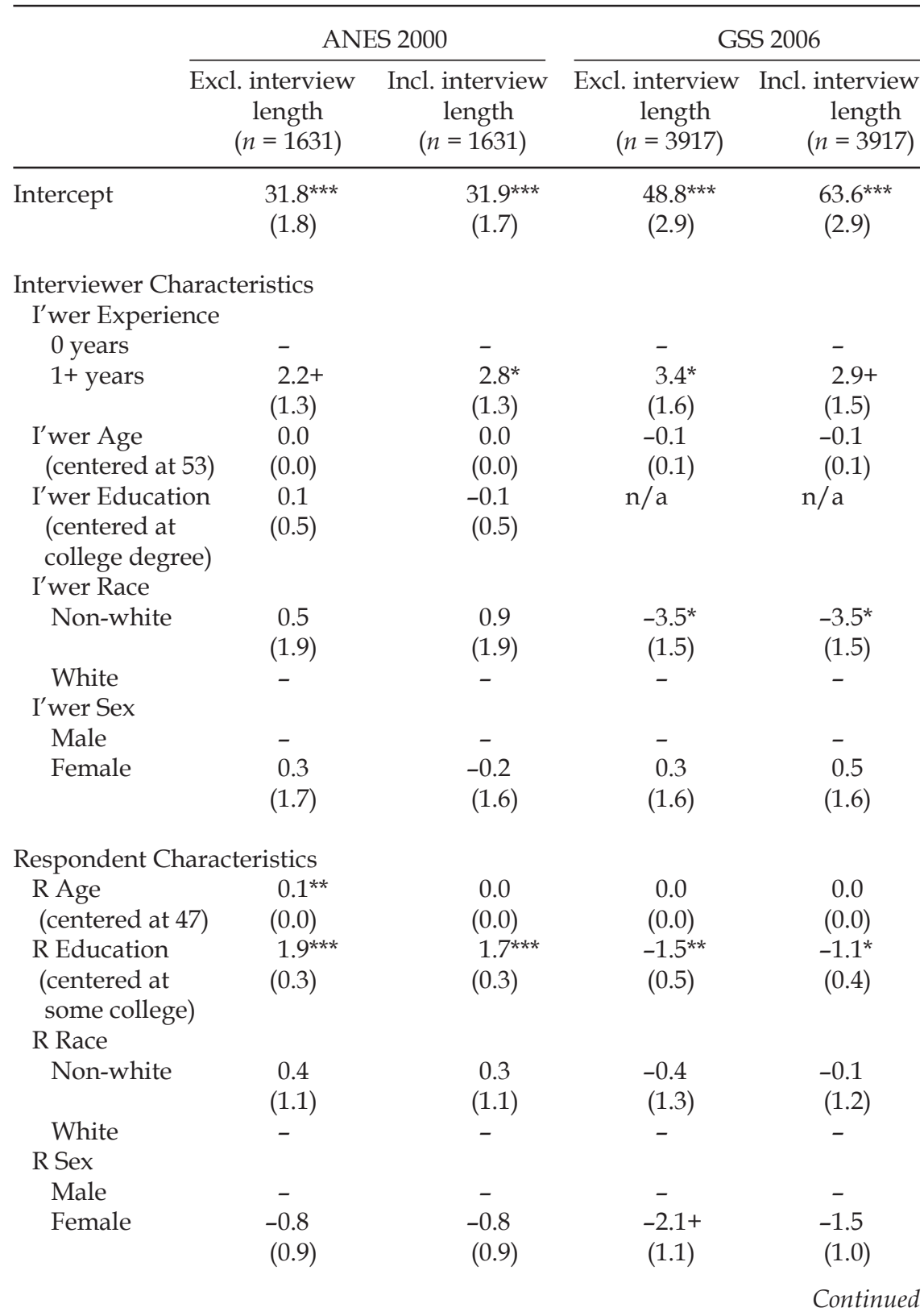


Table 2. Continued.

\begin{tabular}{|c|c|c|c|c|}
\hline & \multicolumn{2}{|c|}{ ANES 2000} & \multicolumn{2}{|c|}{ GSS 2006} \\
\hline & $\begin{array}{l}\text { Excl. interview } \\
\text { length } \\
(n=1631)\end{array}$ & $\begin{array}{l}\text { Incl. interview } \\
\text { length } \\
(n=1631)\end{array}$ & $\begin{array}{c}\text { Excl. interview } \\
\text { length } \\
(n=3917)\end{array}$ & $\begin{array}{c}\text { Incl. interview } \\
\text { length } \\
(n=3917)\end{array}$ \\
\hline \multicolumn{5}{|l|}{ Mode } \\
\hline Face-to-face & $\begin{array}{c}-1.3 \\
(1.1)\end{array}$ & $\begin{array}{c}-1.9 \\
(1.0)\end{array}$ & $\begin{array}{l}-0.4 \\
(2.2)\end{array}$ & $\begin{array}{c}0.8 \\
(2.1)\end{array}$ \\
\hline Telephone & - & - & - & - \\
\hline $\begin{array}{l}\text { Ln (Interview Len } \\
\text { (centered) }\end{array}$ & ength) & $\begin{array}{l}9.2^{* * *} \\
(1.6)\end{array}$ & & $\begin{array}{c}0.9 \\
(1.7)\end{array}$ \\
\hline \multicolumn{5}{|l|}{ Questionnaire } \\
\hline Version 1 & & $\mathrm{n} / \mathrm{a}$ & & $\begin{array}{c}-26.1^{* * *} \\
(1.7)\end{array}$ \\
\hline Version 2 & & $\mathrm{n} / \mathrm{a}$ & & $\begin{array}{c}-32.9^{* * *} \\
(1.9)\end{array}$ \\
\hline Version 3 & & $\mathrm{n} / \mathrm{a}$ & & $\begin{array}{c}-11.8^{* * *} \\
(1.9)\end{array}$ \\
\hline Version 4 & & $\mathrm{n} / \mathrm{a}$ & & $\begin{array}{c}-27.6^{* * *} \\
(1.8)\end{array}$ \\
\hline Version 5 & & $\mathrm{n} / \mathrm{a}$ & & $\begin{array}{c}-32.8^{* * *} \\
(1.9)\end{array}$ \\
\hline Version 6 & & $\mathrm{n} / \mathrm{a}$ & & $\begin{array}{c}-12.9^{* * *} \\
(1.9)\end{array}$ \\
\hline Version 7 & & & & - \\
\hline \multicolumn{5}{|c|}{ Variance Components } \\
\hline Residual Varianc & nce $322.3^{* * *}$ & $316.6^{* * *}$ & $1105.2^{* * *}$ & $930.3^{* * *}$ \\
\hline Intercept Varian & nce & 1.1 & $9.2^{*}$ & $13.1^{* *}$ \\
\hline \multicolumn{5}{|l|}{ Model Fit } \\
\hline AIC & 14084.8 & 14053.0 & 38617.4 & 37972.2 \\
\hline $\mathrm{BIC}$ & 14116.3 & 14086.9 & 38650.7 & 38024.8 \\
\hline
\end{tabular}


Table 3. Hierarchical Linear Model Regression Coefficients and Standard Errors, Variance Components, and Model Fit Statistics for the Interview Length Models, 2000 American National Election Studies and 2006 General Social Survey (standard errors in parentheses)

\begin{tabular}{lcc}
\hline & $\begin{array}{c}\text { ANES 2000 } \\
(n=1631)\end{array}$ & $\begin{array}{c}\text { GSS 2006 } \\
(n=3954)\end{array}$ \\
\hline Intercept & $\begin{array}{c}68.2^{* * *} \\
(4.7)\end{array}$ & $\begin{array}{c}90.2^{* * *} \\
(5.5)\end{array}$ \\
Interviewer Characteristics & & \\
I'wer Experience & - & - \\
0 years & $-6.1+$ & $-8.1^{*}$ \\
1+ years & $(3.5)$ & $(3.9)$ \\
& 0.0 & $0.6^{* * *}$ \\
I'wer Age (centered at 53) & $(0.1)$ & $(0.2)$ \\
& 0.7 & $\mathrm{n} / \mathrm{a}$ \\
I'wer Education & $(1.3)$ & \\
(centered at college degree) & & 0.8 \\
I'wer Race & -4.1 & $(3.7)$ \\
Non-white & $(4.9)$ & - \\
White & - & - \\
I'wer Sex & & $10.5^{*}$ \\
Male & - & $(4.4)$ \\
Female & 2.7 &
\end{tabular}

Respondent Characteristics

R Age (centered at 47)

$0.4^{* * *} \quad 0.2^{* * *}$

(0.0)

(0.0)

R Education

$1.2^{* * *}$

$1.7^{* * *}$

(centered at some college)

(0.3)

R Race

Non-white

1.0

0.5

(1.3)

(1.3)

White

R Sex

Male

Female

0.2

$-0.8$

Mode

(1.0)

(1.0)

Face-to-face

Telephone 
Table 3. Continued.

\begin{tabular}{llc}
\hline & $\begin{array}{c}\text { ANES 2000 } \\
(n=1631)\end{array}$ & $\begin{array}{c}\text { GSS 2006 } \\
(n=3954)\end{array}$ \\
\hline $\begin{array}{l}\text { Variance Components } \\
\text { Residual Variance }\end{array}$ & $375.1^{* * *}$ & $895.0^{* * *}$ \\
Intercept Variance & $116.7^{* * *}$ & $273.8^{* * *}$ \\
Model Fit & & \\
AIC & 14480.5 & 38391.3 \\
BIC & 14512.0 & 38424.5 \\
\hline
\end{tabular}

$+p<0.10 ; * p<0.05 ; * * * p<0.001$ using a two-tailed test; $\mathrm{n} / \mathrm{a}$ indicates variable not available for that study.

whether differently paced interviews mediate the association between interviewer experience and acquiescence.

Respondent and interviewer age and education and length of interview are grand mean centered, easing interpretation of the intercept for the average interviewer and respondent in each study (Raudenbush and Bryk 2002). Dummy variables are used for all dichotomous predictors. In sum, the models are

$$
\begin{aligned}
& Y_{i j}=\beta_{0 j}+\beta_{1}\left(R_{A g e}-\bar{R} A g e\right)+\beta_{2}\left(R E d u c_{i j}-\bar{R} E d u c a t i o n\right)+\beta_{3} \text { RRace }_{i j}+\beta_{4}
\end{aligned}
$$

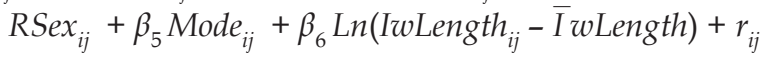

$$
\begin{aligned}
& \beta_{0 j}=\gamma_{0}+\gamma_{1} \text { IExper }_{j}+\gamma_{2}\left(I A g e_{j}-\bar{I} A g e\right)+\gamma_{3}\left(I E d u \gamma_{j}-\bar{I} E d u c\right)+\gamma_{4} I R a c e_{j}+\gamma_{4} \\
& \operatorname{ISex}_{j}+u_{j}
\end{aligned}
$$

\section{Findings}

In the ANES, 1.3 percent $\left(\chi^{2}=2.33,1\right.$ d.f., $\left.p=0.13\right)$, and in the GSS, 1.2 percent of the variance in acquiescence $\left(\chi^{2}=11.23,1\right.$ d.f., $\left.p<.001\right)$ resulted from variation across interviewers. This $\rho_{\text {int }}$ is of similar magnitude to that found for substantive survey variables of interest (Groves and Magilavy 1986).

We expect that more experienced interviewers will have higher rates of acquiescence than inexperienced interviewers. This is what we find in both studies. When experience is added to the null model, it explains 39 percent of the variance in acquiescence across interviewers in the ANES and 12 percent in the GSS. The relationship between acquiescence and experience holds when accounting for interviewer and respondent characteristics and for interview length (Table 2). In the GSS, respondents who are interviewed by experienced interviewers have, on average, 3.4 percent $(\mathrm{SE}=1.6, p<.05)$ more acquiescent answers than those who are interviewed by inexperienced interviewers. This difference is 2.2 percent in the ANES (SE = 1.3, $p<.10)$. After accounting for respondent and interviewer characteristics, there is no longer statistically significant variation across interviewers in the ANES $\left(\rho_{\text {int }}=0.003\right)$, 
although the variability across interviewers in the GSS is of similar magnitude $\left(\rho_{\text {int }}=0.014\right)$.

Interviewers with some experience have faster interviews in both studies (Table 3). In the ANES, more experienced interviewers are, on average, six minutes $(\mathrm{SE}=3.5, p<.10)$ faster than inexperienced interviewers; the difference is eight minutes ( $\mathrm{SE}=3.9, p<.05$ ) in the GSS. To mediate the relationship between experience and acquiescence, including length of interview in the acquiescence model should reduce or eliminate the experience coefficient (Baron and Kenny 1986). Yet in each study, the relationship between experience and acquiescence holds after accounting for the length of interview and, in fact, increases in the ANES.

Other interviewer characteristics are not consistently related to acquiescence. Non-white interviewers obtain fewer acquiescent answers than do white interviewers in the GSS (beta $=-3.5, \mathrm{SE}=1.5, p=0.02$ ), but not in the ANES, likely due to the inclusion of race-related questions in the GSS acquiescence measure (Krysan and Couper 2003). No association was found between acquiescence and interviewer sex, age, or education.

Respondent characteristics are also inconsistently related to acquiescence across the two studies. Faster interviews had much higher acquiescence rates in both studies. Respondents with higher levels of education provide more acquiescent answers (beta $=1.7, \mathrm{SE}=0.3, p<.001$ ) in the ANES, ${ }^{4}$ but lower levels in the GSS (beta $=-1.1, \mathrm{SE}=0.4, p<.05$ ). In comparison to experience, education alone explains 19 percent of the variance across interviewers in the ANES and less than one percent of the variance in the GSS. The effect of respondent age disappears in the ANES after accounting for length of interview and is not significant in the GSS. No statistical relationship $(p<.05)$ between acquiescence and respondent race, sex, or mode of administration is found in either survey.

\section{Discussion}

More experienced interviewers obtain higher levels of acquiescent reports than do inexperienced interviewers. Two hypotheses - an increased pace of interview and a desire to maintain rapport with respondents - were posited as potential mechanisms for this association. After accounting for length of interview, a relationship between experience and acquiescence was maintained in both studies. This suggests that experienced interviewers may have higher levels of rapport or engage in other acquiescence-encouraging behaviors with respondents than inexperienced interviewers.

As with any study, this analysis has limitations. First, we examined the effects of general interviewer experience in large, ongoing, national face-to-face studies. We cannot disentangle general interviewer experience from prior

4 .The direction of this coefficient is positive in the original Holbrook, Green, and Krosnick (2003) analyses. 
ANES or GSS experience. Second, the sample was not released in random replicates across the study period, confounding sample composition with difficulty in recruiting. Thus, we cannot examine potential changes in these data quality measures over the course of the data collection period (e.g., Olson and Peytchev 2007). Third, although we hypothesize that there are meaningful differences in interviewer behaviors between experienced and inexperienced interviewers, we have no direct measures of these behaviors. Finally, although we accounted for meaningful respondent characteristics that may affect reports of each type of reporting behavior, lack of interpenetration prevents us from disentangling interviewer effects from sampling area effects. However, we still feel confident in the results from this analysis given the replication of findings across two surveys.

Interviewer experience explains more variance in acquiescence in both studies than does respondent education. This finding has both theoretical and practical implications. Models for acquiescence (Holbrook, Green, and Krosnick 2003; Schuman and Presser 1981) focus on respondent characteristics, but tend to ignore the role of the interviewer. These results suggest that interviewers may learn behaviors as they gain experience that unintentionally may affect attitudinal reports. We hypothesize that those behaviors, both verbal and nonverbal, increase rapport and thus increase acquiescence. Additionally, interviewers are trained to obtain cooperation by establishing rapport with sampled households (e.g., Morton-Williams 1993); experienced interviewers may be more likely to use rapport-based approaches during recruitment than inexperienced interviewers. Once the householder agrees to the survey request, the interviewer is expected to use neutral yet motivating behaviors consistent with standardized interviewing techniques (e.g., Fowler and Mangione 1990). This contradiction in tasks increases "interviewer burden" (Japec 2008), potentially leading to a tradeoff between nonresponse rates and acquiescence.

What do these results mean for training and monitoring interviewers? First, both inexperienced and experienced interviewers should receive training in basic interviewing techniques, including pace of administering the interview and neutral interview behaviors. Second, survey organizations conducting large numbers of attitudinal surveys should monitor and evaluate interviewers for behaviors that seem to encourage more acquiescence during respondent recruitment, although this is easier to accomplish in a centralized telephone facility than in face-to-face studies. Additionally, interviewer-level variability in acquiescence rates should be monitored during the course of the data collection, especially if key statistics are estimated from "yes/no" or "agree/disagree" questions. Finally, retraining all interviewers during the course of data collection may be necessary to reinforce good interviewing practices.

As an acquired characteristic, interviewer experience effects are likely to differ across survey organizations. Yet in this analysis, the relationship between interviewer experience and acquiescence was consistent across two studies. As such, the meaning of an "experienced interviewer" seems similar across organizations. We know little about who becomes an experienced 
interviewer either by choice or selection by the survey organization (see Link 2006 for an exception). To fully understand the effect of experience on data quality, future research should examine how interviewers gain experience across survey organizations.

\section{Appendix}

ANES 2000 Questions: Questions found in the ANES 2000 codebook (Burns et al. 2002). The scale was derived following Holbrook, Green, and Krosnick (2003).

F0: Now we would like to know something about the feelings you have toward the candidates for president. I am going to name a candidate, and I want you to tell me whether something about that person, or something he has done, has made you have certain feelings like anger or pride.

F1: (Think about Al Gore.) Has Al Gore (because of the kind of person he is, or because of something he has done) ever made you feel:
A. Angry
B. Hopeful
C. Afraid
D. Proud

F2: (Think about George W. Bush.) Has George W. Bush (because of the kind of person he is, or because of something he has done) ever made you feel:
A. Angry
B. Hopeful
C. Afraid
D. Proud

F3: (Think about Pat Buchanan.) Has Pat Buchanan (because of the kind of person he is, or because of something he has done) ever made you feel:
A. Angry
B. Hopeful
C. Afraid
D. Proud

Q14: Has Bill Clinton (because of the kind of person he is or because of something he has done) ever made you feel:
A. Angry
B. Hopeful
C. Afraid
D. Proud 
H12: Do you agree or disagree with this statement: This country would be better off if we just stayed home and did not concern ourselves with problems in other parts of the world.

L6: Some people think that if a company has a history of discriminating against blacks when making hiring decisions, then they should be required to have an affirmative action program that gives blacks preference in hiring. What do you think? Should companies that have discriminated against blacks have to have an affirmative action program?

GSS 2006 Questions: Questions from the GSS codebook (Davis and Smith 2007).

206. Please tell me whether or not you think it should be possible for a pregnant woman to obtain a legal abortion if... READ EACH STATEMENT AND CIRCLE ONE CODE FOR EACH.

A. The woman's own health is seriously endangered by the pregnancy?

B. The family has a very low income and cannot afford any more children?

C. She became pregnant as a result of rape?

D. The woman wants it for any reason?

232. Are there any situations you can imagine in which you would approve of a policeman striking an adult male citizen?
A. Had said vulgar and obscene things to the policeman?
B. Was being questioned as a suspect in a murder case?
C. Was attempting to escape from custody?
D. Was attacking the policeman with his fists?

227. Do you think a person has the right to end his or her own life if this person ... READ EACH STATEMENT AND CIRCLE ONE CODE FOR EACH.
A. Has an incurable disease?
B. Has gone bankrupt?
C. Has dishonored his or her family?
D. Is tired of living and ready to die?

266. On the average (Blacks/African Americans) have worse jobs, income, and housing than white people. Do you think these differences are ...

A. Mainly due to discrimination?

B. Because most (Blacks/African Americans) have less inborn ability to learn?

C. Because most (Blacks/African Americans) don't have the chance for education that it takes to rise out of poverty?

D. Because most (Blacks/African Americans) just don't have the motivation or willpower to pull themselves up out of poverty? 
202. A. Tell me if you agree or disagree with this statement: Most men are better suited emotionally for politics than are most women.

178. Now I'm going to read you several more statements. Some people agree with a statement, and others disagree. As I read each one, tell me whether you more or less agree with it, or more or less disagree. A. Most public officials (people in public office) are not really interested in the problems of the average man.

\section{References}

Bailar, Barbara, Leroy Bailey, and Joyce Stevens. 1977. "Measures of Interviewer Bias and Variance." Journal of Marketing Research 14:337-43.

Baron, Reuben M., and David A. Kenny. 1986. “The Moderator-mediator Variable Distinction in Social Psychological Research: Conceptual, Strategic, and Statistical Considerations." Journal of Personality and Social Psychology 51:1173-82.

Burns, Nancy, Donald R. Kinder, Steven J. Rosenstone, Virginia Sapiro, and the National Election Studies. 2002. "American National Election Study, 2000: Preand Post-election Survey" [computer file]. Ann Arbor, MI: University of Michigan, Center for Political Studies.

Chromy, James R., Joe Eyerman, Dawn Odom, McNeeley E. Madeline, and Art Hughes. 2005. "Association between Interviewer Experience and Substanceuse Prevalence Rates in NSDUH." pp. 59-87 in Evaluating and Improving Methods Used in the National Survey on Drug Use and Health, (DHHS Publication No. SMA 05-4044, Methodology Series M-5), Joel Kennet and Joseph Gfroerer, eds. Rockville, MD: Substance Abuse and Mental Health Services Administration, Office of Applied Studies.

Cleary, Paul D., David Mechanic, and Norma Weiss. 1981. "The Effect of Interviewer Characteristics on Responses to a Mental Health Interview." Journal of Health and Social Behavior 22:183-93.

Davis, Darren W. 1997. “Nonrandom Measurement Error and Race of Interviewer Effects among African Americans." Public Opinion Quarterly 61:183-207.

Davis, James A., and Tom W. Smith. 2007. General Social Surveys, 1972- 2006. [machine-readable data file]. Principal Investigator, James A. Davis; Director and Co-principal Investigator, Tom W. Smith; Co-principal Investigator, Peter V. Marsden, NORC ed. Chicago: National Opinion Research Center, Producer, 2005; Storrs, CT: The Roper Center for Public Opinion Research, University of Connecticut, Distributor. 1 data file (51,020 logical records) and 1 codebook (2,552 pp).

Dijkstra, Wil. 1983. "How Interviewer Variance Can Bias the Results of Research on Interviewer Effects." Quality and Quantity 17:179-87.

Fowler, Floyd J., and Thomas W. Mangione. 1990. Standardized Interviewing: Minimizing Interviewer-related Error. Newbury Park: Sage.

Goudy, Willis J., and Harry Potter R. 1975-76. "Interview Rapport: Demise of a Concept." Public Opinion Quarterly 39:529-43.

Groves, Robert M., and Mick Couper. 1998. Nonresponse in Household Interview Surveys. New York: John Wiley \& Sons, Inc. 
Groves, Robert M., Floyd J. Fowler, Mick P. Couper, James M. Lepkowski, Eleanor Singer, and Roger Tourangeau. 2004. Survey Methodology. New York: John Wiley \& Sons, Inc.

Groves, Robert M., and Nancy H. Fultz. 1985. “Gender Effects among Telephone Interviewers in a Survey of Economic Attitudes." Sociological Methods \& Research 14:31-52.

Groves, Robert M., and Lou J. Magilavy. 1986. "Measuring and Explaining Interviewer Effects in Centralized Telephone Surveys." Public Opinion Quarterly 50:251-66.

Holbrook, Allyson L, Melanie C. Green, and Jon A. Krosnick. 2003. "Telephone versus Face-to- Face Interviewing of National Probability Samples with Long Questionnaires." Public Opinion Quarterly 67:79-125.

Houtkoop-Steenstra, Hanneke. 1996. "Probing Behavior of Interviewers in the Standardized Semi- Open Research Interview." Quality and Quantity 30:205-30.

Houtkoop-Steenstra, Hanneke. 1997. "Being Friendly in Survey Interviews." Journal of Pragmatics 28:591-623.

Houtkoop-Steenstra, Hanneke, and Charles Antaki. 1997. "Creating Happy People by Asking Yes-No Questions." Research on Language $\mathcal{E}$ Social Interaction 30:285-313.

Hox, Joop J. 1994. "Hierarchical Regression Models for Interviewer and Respondent Effects." Sociological Methods E Research 22:300-318.

Hox, Joop J., Edith D. De Leeuw, and Ita G. Kreft. 1991. “The Effect of Interviewer and Respondent Characteristics on the Quality of Survey Data: A Multilevel Model". In Measurement Errors in Surveys, eds. P. P. Biemer, R. M. Groves, L. E. Lyberg, N. A. Mathiowetz and S. Sudman, 439-61. New York: John Wiley.

Hughes, Arthur, James Chromy, Katherine Giacoletti, and Dawn Odom. 2002. "Impact of Interviewer Experience on Respondent Reports of Substance Use." In Redesigning an Ongoing National Household Survey, ed. Joseph Gfroerer, Joe Eyerman, and James Chromy, Washington, DC: Substance Abuse and Mental Health Services Administration. 161-84.

Japec, Lilli. 2008. "Interviewer Error and Interviewer Burden." In Advances in Telephone Survey Methodology, ed. James M. Lepkowski, Clyde Tucker, J. Michael Brick, Edith de Leeuw, Lilli

Japec, Paul J. Lavrakas, Michael W. Link, Roberta L. Sangster. Hoboken, NJ: John Wiley \& Sons, Inc. 187-211.

Johnson, Timothy P., Michael Fendrich, Chitra Shaligram, Anthony Garcy, and Samuel Gillespie. 2000. "An Evaluation of the Effects of Interviewer Characteristics in an RDD Telephone Survey of Drug Use." Journal of Drug Issues 30:77-101.

Kahn, Robert L., and Charles F. Cannell. 1957. The Dynamics of Interviewing: Theory, Technique, and Cases. New York: Wiley.

Kane, Emily W., and Laura J. Macaulay. 1993. “Interviewer Gender and Gender Attitudes." Public Opinion Quarterly 57:1-28.

Kish, Leslie. 1962. "Studies of Interviewer Variance for Attitudinal Variables." Journal of the American Statistical Association 57:92-115.

Knauper, Barbel, Norbert Schwarz, Denise Park, and Andreas Fritsch. 1997. "The Perils of Interpreting Age Differences in Attitude Reports: Question Order Effects Decrease with Age." Journal of Official Statistics 13:181-99. 
Krosnick, Jon A. 2002. "The Causes of No-opinion Responses to Attitude Measures in Surveys: They Are Rarely What They Appear to Be." In Survey Nonresponse, ed. Robert M. Groves, Donald A. Dillman, John L. Eltinge, and Roderick J. A. Little, New York: John Wiley \& Sons, Inc. 87-100.

Krysan, Maria, and Mick P. Couper. 2003. "Race in the Live and the Virtual Interview: Racial Deference, Social Desirability, and Activation Effects in Attitude Surveys." Social Psychology Quarterly 66:364-83.

Link, Michael W. 2006. "Predicting the Persistence and Performance of Newly Recruited Telephone Interviewers." Field Methods 18:305-20.

Mahalanobis, Prasanta C. 1946. "Recent Experiments in Statistical Sampling in the Indian Statistical Institute." Journal of the Royal Statistical Society 109:326-78.

Morton-Williams, Jean. 1993. Interviewer Approaches. Cambridge, UK: University Press.

Narayan, Sowmya, and Jon A. Krosnick. 1996. "Education Moderates Some Response Effects in Attitude Measurement." Public Opinion Quarterly 60:58-88.

Olson, Kristen, and Andy Peytchev. 2007. "Effect of Interviewer Experience on Interview Pace and Interviewer Attitudes." Public Opinion Quarterly 71:273-86.

O'Muircheartaigh, Colm, and Pamela Campanelli. 1998. "The Relative Impact of Interviewer Effects and Sample Design Effects on Survey Precision." Journal of the Royal Statistical Society. Series A (Statistics in Society) 161:63-77.

Raudenbush, Stephen W., and Anthony S. Bryk. 2002. Hierarchical Linear Models: Applications and Data Analysis Methods. Newbury Park, CA: Sage.

Ross, Catherine E., and John Mirowsky. 1984. "Socially Desirable Response and Acquiescence in a Cross-cultural Survey of Mental Health." Journal of Health and Social Behavior 25:189-97.

Schuman, Howard, and Jean M. Converse. 1971. "The Effects of Black and White Interviewers on Black Responses in 1968." Public Opinion Quarterly 35:44-68.

Schuman, Howard, and Stanley Presser. 1981. Questions and Answers in Attitude Surveys. New York: Academic Press.

Singer, Eleanor, Martin, R. Frankel, and Marc B. Glassman. 1983. "The Effect of Interviewer Characteristics and Expectations on Response." Public Opinion Quarterly 47:68-83.

Smith, David H. 1967. "Correcting for Social Desirability Response Sets in Opinionattitude Survey Research." Public Opinion Quarterly 31:87-94.

Tarnai, John, and Danna L. Moore. 2008. "Measuring and Improving Telephone Interviewer Performance and Productivity." In Advances in Telephone Survey Methodology, ed. James M. Lepkowski, Clyde Tucker, J. Michael Brick, Edith D. De Leeuw, Lilli Japec, Paul J. Lavrakas, Michael W. Link, Roberta L. Sangster. Hoboken, NJ: John Wiley \& Sons, Inc. 359-84.

Webster, Cynthia. 1996. "Hispanic and Anglo Interviewer and Respondent Ethnicity and Gender: The Impact on Survey Response Quality." Journal of Marketing Research 33:62-72.

Weiss, Carol H. 1968-69. “Validity of Welfare Mothers' Interview Responses.” Public Opinion Quarterly 32:622-33. 